http://jmscr.igmpublication.org/home/ ISSN (e)-2347-176x ISSN (p) 2455-0450

crossref DOI: https://dx.doi.org/10.18535/jmscr/v7i11.54

\title{
Comparison of Inguinal Versus Classic Approach for Obturator Nerve Block in Transurethral Resection of Bladder Tumour
}

\author{
IGM Publication \\ Journal Of Medical Science And Clinical Research \\ An Official Publication of IGM Publication
}

\author{
Authors \\ Dr Ganga $\mathbf{G}^{1}$, Dr Hari Dev J.J ${ }^{2}$
}

${ }^{1}$ Associate Professor, Department of Anesthesiology, Govt. Medical College, Kottayam

${ }^{2}$ Senior Resident, Department of Anesthesiology, Govt. Medical College, Kottayam

\begin{abstract}
Background \& Objectives: Trans Urethral Resection of Bladder Tumour (TURBT) is a procedure in which bladder tumors can be removed from the bladder wall and the procedure is performed completely with a resectoscope that is inserted through the urethra into the bladder. The obturator nerve, which arises from the ventral divisions of the second, third, and fourth lumbar nerves, passes in close proximity to the infero lateral bladder wall, bladder neck and lateral prostatic urethra.

During transurethral resection of bladder tumours (TURBT) under spinal anaesthesia, electrical resection of the lateral wall mass may cause violent adductor contraction and possible inadvertent bladder perforation, vessel laceration, incomplete tumour resection, and obturator hematomas. Therefore, Obturator Nerve Block (ONB) is mandatory after spinal anaesthesia for TURBT.

Our study was undertaken to compare Success Rate* and Ease of Block** of Inguinal and Classic approach for obturator nerve block in patients undergoing transurethral resection of bladder tumour under spinal anaesthesia.

*Number of cases in which Obturator reflex or Adductor spasm is prevented after administration of block **Number of attempts required to elicit Adductor muscle contraction using peripheral nerve stimulator and to administer local anaesthetic.
\end{abstract}

Methodology: 80 patients aged 40-90 years belonging to ASA PS - I \& II of both sexes undergoing Transurethral Resection of Bladder Tumour under Spinal anesthesia were included in our study. Patients satisfying the inclusion criteria were allotted into 2 groups of 40 each.

Group 1: Patients received obturator nerve block via classic approach

Group 2: Patients received obturator nerve block via inguinal approach

Results: In our study, we found that the success rate of obturator nerve block by the inguinal approach was higher with less incidence of Adductor spasm (7.5\%) compared to the classic group (25\%) and the ease of block was higher for the inguinal group in which the mean number of puncture attempts was less $(1.85 \pm 0.834)$ compared to classic group $(2.45 \pm 0.932)$

Conclusion: From our study we conclude that the Inguinal approach for obturator nerve block appeared to be an easily performable block with a high success rate compared to the Classic approach.

Keywords: Obturator nerve block, Transurethral resection, Obturator reflex, Adductor spasm.

\section{Introduction}

Endoscopic treatment with transurethral resection of bladder tumour (TURBT) is the first-line treatment to diagnose, stage, and treat visible tumours. This technique is performed with a resectoscope, which is a cauterisation loop that 
uses electrical currents for resection. The obturator nerve, arising from the ventral divisions of the second, third, and fourth lumbar nerves, passes close to the infero lateral wall of the bladder. So in tumours involving the inferior or lateral wall of the bladder, the electrical currents from the resectoscope may stimulate the obturator nerve that may lead to contraction of adductor muscles in thigh. This sudden jerk or contraction may cause abrupt movements during instrumentation that can lead to undesirable complications such as bladder perforation, vascular injuries, incomplete tumour resection and obturator hematomas.

Recently, Choquet et al $^{6}$ described a simple and reliable new method known as the inguinal approach for ONB, in which the needle is inserted at the mid-point of the line drawn at the inguinal crease joining the femoral arterial pulse and the inner side of the adductor longus tendon. The present study sought to compare the success rate and ease of block in terms of prevention of adductor jerk/obturator reflex and number of attempts to achieve block respectively, between the classic and inguinal approaches for ONB.

\section{Objectives}

To compare the success rate and ease of block of classic and inguinal approach for obturator nerve block in patients undergoing transurethral resection of bladder tumour under spinal anesthesia.

Success rate was defined as the number of cases in which adductor jerk/obturator reflex is prevented after administration of block.

Ease of block was defined by the number of attempts required to elicit adductor muscle contraction using peripheral nerve stimulator in order to locate the nerve.

\section{Materials and Methods}

\section{Study Design}

Descriptive Study

\section{Study Duration}

12 months

\section{Study Setting}

Major operation theatre, Government Medical College, Kottayam

\section{Study Population}

Eighty patients of age 40-90 years of both sexes of ASA -1 and ASA-2 category undergoing transurethral resection of bladder tumour under spinal anaesthesia at Govt. Medical College Kottayam.

\section{Sample Size}

Based on the data from a comparative study conducted by Youn Yi Jo et al minimum sample size was calculated using the formula,

$$
\left.\mathrm{N}=\frac{(\mathrm{Z}}{\alpha} \underline{\alpha}+Z_{\beta}\right)^{2} \times[(\mathrm{S} 1+\mathrm{S} 2) \div 2]^{2} \times 2
$$

$\mathrm{Z}_{\alpha}=1.96$ ( $\alpha$ at 95\%), Standard deviation S1 = 0.9 , Mean M1 = 1.8 (Group with Classic approach)

$Z_{\beta}=0.84 \quad(\beta$ at $80 \%)$, Standard deviation $\mathrm{S} 2=$ 0.6 , Mean $\mathrm{M} 2=1.3$ ( Group with inguinal approach)

$$
\mathrm{N}=\frac{(1.96+0.84)^{2} \times 2 \times(0.75)^{2}}{(0.5)^{2}}
$$

$\mathrm{N}=35 \sim 40$

Hence the study was conducted with a sample size of $\mathbf{4 0}$ in each group.

\section{Study Tool}

- Interview schedule

- ECG, NIBP and Pulse Oxymeter.

- Drugs and equipment for spinal anaesthesia, $1 \%$ Lignocaine with Adrenaline and $0.25 \%$ Bupivacaine

- 18 gauge cannula, 21 G Stimuplex ${ }^{\circledR}$ Needle and Peripheral Nerve stimulator.

\section{Inclusion Criteria}

Adult patients of ASA Grade I, II, aged between 40-90 years of both sexes, undergoing transurethral resection of bladder tumour under spinal anesthesia.

\section{Exclusion Criteria}

1) Patient refusal

2) Known case of hypersensitivity to local anaesthetics 
3) Perineal infection or hematoma at the needle insertion site

4) Previous surgery or scars in the region

5) Patients on anticoagulants

6) Patients of ASA- PS 3 and 4

\section{Observations}

Patients satisfying the inclusion criteria, posted for TURBT were administered spinal anaesthesia with bupivacaine and were taken consecutively for obturator nerve block via classic and inguinal approach until a sample size of 40 were obtained in each group. ONB was administered using peripheral nerve stimulator with lignocaine and bupivacaine. Adductor jerk/obturator reflex during surgery was noted if present. Number of attempts to locate the nerve, depth of needle insertion, and accidental arterial puncture if occurred was also noted.

\section{Data Management and Analysis}

Data was coded and entered in Microsoft Excel and analyzed using IBM SPSS with descriptive statistics using mean, standard deviation, frequency and percentages. Chi-square test was applied for qualitative variables, independent sample $t$ test and one way ANOVA (F test) were used for quantitative variables. The level of statistical significance was p value less than 0.05 .

\section{Study Procedure}

All patients were evaluated and informed written consent was taken. All patients were fasted for 8 hours and premedicated with Tab. Ranitidine 150mg, Tab. Metoclopramide 10mg and Tab. Alprazolam $0.25 \mathrm{mg}$ at night and in the morning of surgery. In the operation theatre intravenous access was secured and fluid started. ECG, NIBP and pulse oximetry were connected to the patient. Baseline pulse, $\mathrm{BP}$ and $\mathrm{SpO} 2$ were recorded.

Patients receiving ONB via classic approach were called Group 1 and those receiving ONB via the inguinal approach were called Group 2. All the ONB procedures were performed by another anesthesiologist, who was not involved in any other patient anesthesia management. All the blocks were performed unilaterally (on the site of tumor). Spinal block was performed using a $23 \mathrm{G}$ Quincke needle at the L3-4 interspace, using 12.5 $\mathrm{mg}(2.5 \mathrm{ml})$ of $0.5 \%$ bupivacaine (Heavy). Thereafter, the sensory block level was checked using an alcohol swab or pin-prick test. When the sensory block level reached above T12, ONB was performed. For both the approaches, patient was positioned supine. Obturator nerve block was performed using peripheral nerve stimulator and nerve stimulation was started using a current of 2$3 \mathrm{~mA}$ ( $2 \mathrm{~Hz}, 0.1-0.3 \mathrm{msec}$ ), and reduced to $0.3-0.5$ $\mathrm{mA}$ before injection of local anaesthetic.

By the classic approach, patient was placed in a supine position with the legs slightly abducted and externally rotated. After identification of the pubic tubercle, the needle was inserted perpendicular to the skin $1.5 \mathrm{~cm}$ lateral and $1.5 \mathrm{~cm}$ inferior to the tubercle. When the needle made contact with the inferior border of the superior pubic ramus, it was withdrawn and slipped along the anterior pubic wall. After this, the needle was slightly withdrawn again and advanced cephalad and laterally at an angle of 45 degree until contraction of the thigh adductor muscles were observed. When the adductor muscle showed contractions, $5 \mathrm{ml}$ of $1 \%$ lignocaine with adrenaline $+5 \mathrm{ml} \quad 0.25 \%$ bupivacaine was administered after confirmation so that no blood was present after negative aspiration.

By the inguinal approach, the patient was placed in supine position with the legs slightly abducted and a line was marked in the inguinal crease. After identification of the adductor longus tendon in the medial part of the thigh, a mark on the skin was made in the inguinal crease at the midpoint of the line drawn between the femoral arterial pulse and the inner border of the adductor longus tendon. This approach was performed in 2 stages. First, the needle was inserted $0.5 \mathrm{~cm}$ below the mark in the cephalad direction with a 30 degree angle to the skin until adductor muscle (adductor longus or gracilis) contractions were elicited. After identification of the contractions (anterior 
side of the inner thigh and the medial part of the knee), $5 \mathrm{ml}$ of $(2.5 \mathrm{ml} 1 \%$ Lignocaine with Adrenaline $+2.5 \mathrm{ml} 0.25 \%$ Bupivacaine) was administered (anterior branch block). Then the needle was advanced deeper about $0.5-1 \mathrm{~cm}$ and 5 degree laterally. When the contraction of the adductor magnus muscle occurred (i.e. noticeable hip adduction), $5 \mathrm{ml}$ of $(2.5 \mathrm{ml} 1 \%$ lignocaine with adrenaline $+2.5 \mathrm{ml} 0.25 \%$ bupivacaine) was injected (posterior branch block).

\section{Results}

Table 1: Depth of needle insertion in classic and inguinal groups

\begin{tabular}{|c|c|c|c|c|c|c|}
\hline & Group & Number & Mean & $\begin{array}{c}\text { Std. } \\
\text { Deviation }\end{array}$ & t value & \\
\hline \multirow{2}{*}{ Depth of needle insertion } & Classic & 40 & 4.138 & 0.3635 & \multirow{2}{*}{4.80} & $\mathrm{p}<0.05$ \\
\cline { 2 - 7 } & Inguinal & 40 & 3.643 & 0.5401 & \multirow{2}{*}{ p } \\
\hline
\end{tabular}

The mean depth of insertion in cms for inguinal group was less (3.643) compared to classic group
(4.138) which was statistically significant with $\mathrm{p}$ value $<0.05$

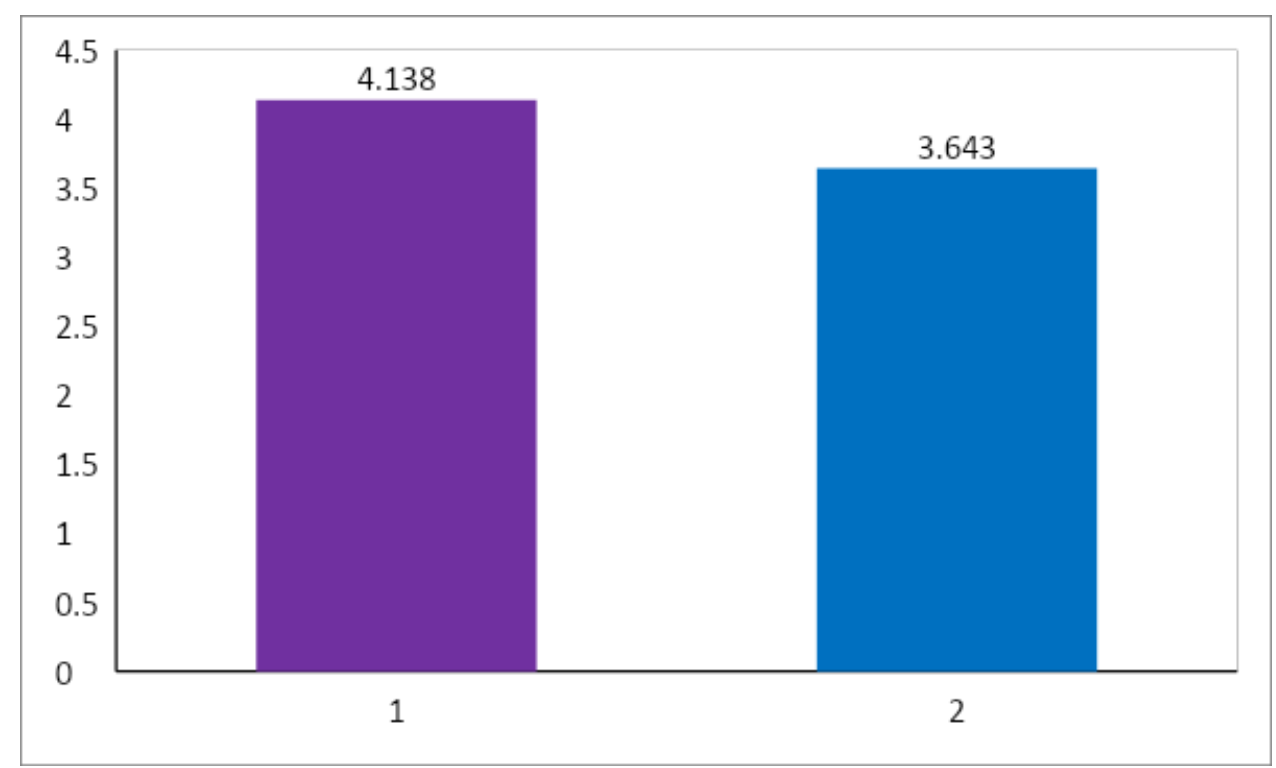

Graph 1: Depth of needle insertion in classic and inguinal groups

Table 2: Incidence of adductor jerk/obturator reflex in classic and inguinal groups

\begin{tabular}{|l|c|c|c|c|}
\hline \multirow{2}{*}{ Group } & & \multicolumn{2}{|c|}{ Adductor jerk } & \multirow{2}{*}{ Total } \\
\cline { 3 - 4 } & & No & Yes & \\
\hline \multirow{2}{*}{ Classic } & Count & 30 & 10 & 40 \\
\cline { 2 - 5 } & $\%$ & $75.0 \%$ & $25.0 \%$ & $100.0 \%$ \\
\hline \multirow{2}{*}{ Inguinal } & Count & 37 & 3 & 40 \\
\cline { 2 - 5 } & $\%$ & $92.5 \%$ & $7.5 \%$ & $100.0 \%$ \\
\hline \multirow{2}{*}{ Total } & Count & 67 & 13 & 80 \\
\cline { 2 - 5 } & $\%$ & $83.8 \%$ & $16.3 \%$ & $100.0 \%$ \\
\hline
\end{tabular}

There was a statistically significant difference in the incidence of adductor jerk $\left({ }^{2}=4.70 \mathrm{p}<0.05\right)$ between the two groups with inguinal group having less incidence of the same $(7.5 \%)$ compared to the classic group (25\%). 


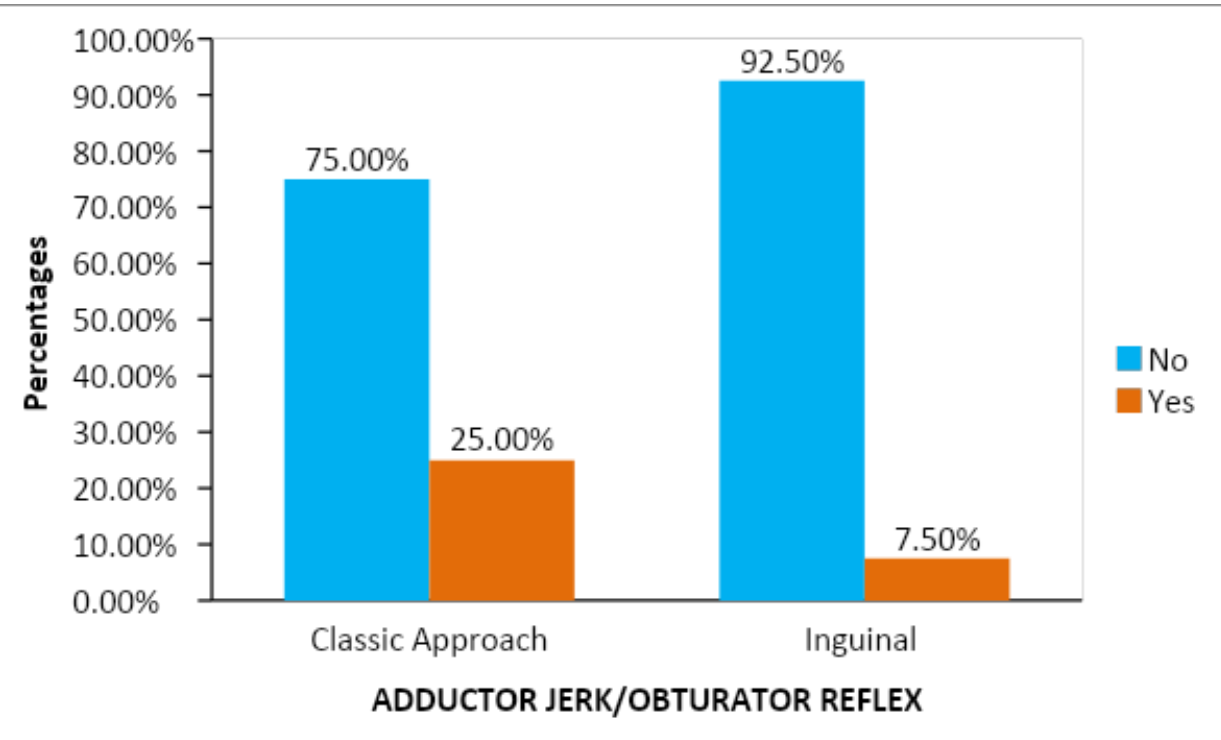

Graph 2: Incidence of adductor jerk/obturator reflex in classic and inguinal groups

Table 3: Number of puncture attempts to locate obturator nerve in both groups

\begin{tabular}{|l|c|c|c|c|c|c|}
\hline \multirow{2}{*}{ Classic } & & \multicolumn{4}{|c|}{ Number of attempts } & \multirow{2}{*}{ Total } \\
\cline { 3 - 6 } & Count & $\mathbf{1}$ time & $\mathbf{2}$ times & 3 times & $\mathbf{4}$ times & \\
\cline { 2 - 7 } & $\%$ & $15.0 \%$ & $40.0 \%$ & $30.0 \%$ & $15.0 \%$ & $100.0 \%$ \\
\hline \multirow{2}{*}{ Inguinal } & Count & 16 & 15 & 8 & 1 & 40 \\
\cline { 2 - 7 } & $\%$ & $40.0 \%$ & $37.5 \%$ & $20.0 \%$ & $2.5 \%$ & $100.0 \%$ \\
\hline \multirow{2}{*}{ Total } & Count & 22 & 31 & 20 & 7 & 80 \\
\cline { 2 - 7 } & $\%$ & $27.5 \%$ & $38.8 \%$ & $25.0 \%$ & $8.8 \%$ & $100.0 \%$ \\
\hline
\end{tabular}

In order to successfully locate the nerve, puncture attempts of "four times", was more with classic approach while "single puncture" attempt which resulted in successful location of the nerve was more with inguinal approach and was statistically significant. $\left({ }^{2}=9.51 \mathrm{p}<0.05\right)$.

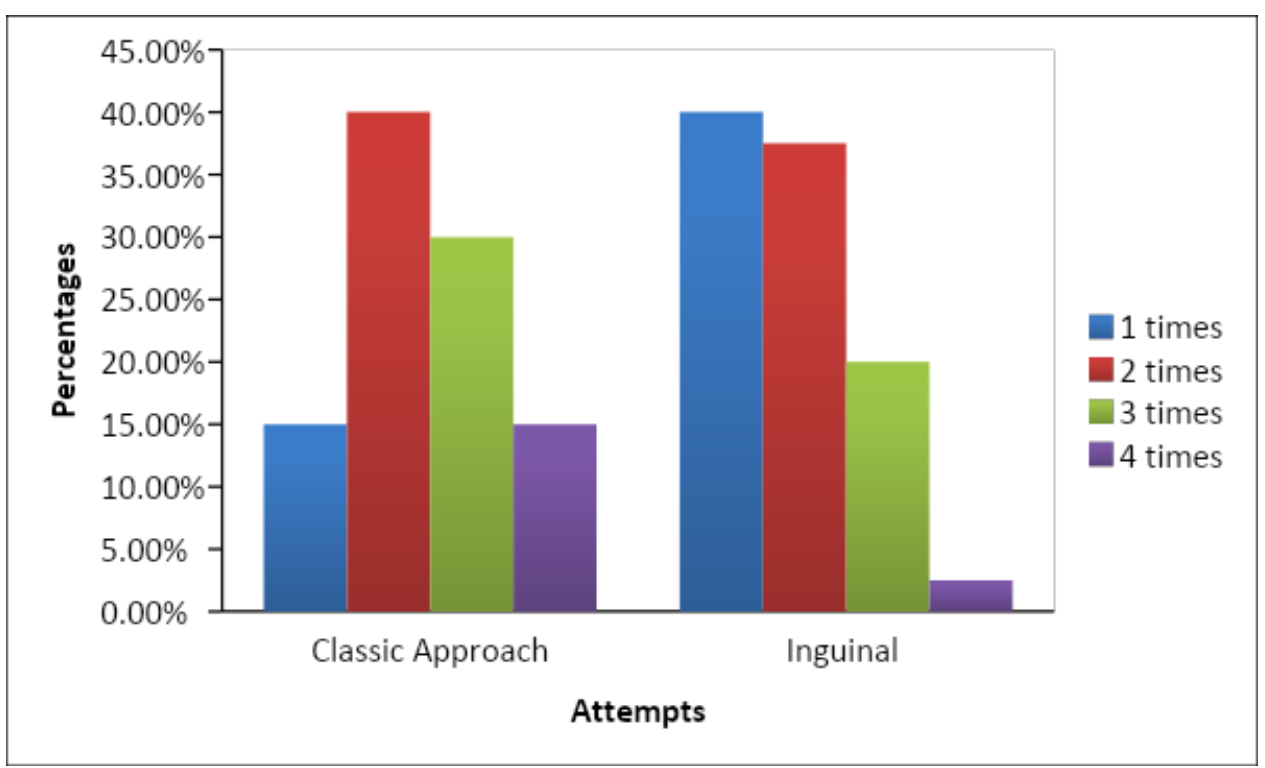

Graph 3: Number of puncture attempts to locate obturator nerve in both groups 


\section{JMSCR Vol||07||Issue||11||Page 319-328||November}

Table 4: Mean number of puncture attempts to locate obturator nerve in both groups

\begin{tabular}{|c|l|l|l|l|l|l|}
\hline & Group & N & Mean & Std. Deviation & t value & p value \\
\hline \multirow{2}{*}{$\begin{array}{c}\text { Number of } \\
\text { attempts }\end{array}$} & Classic & 40 & 2.45 & 0.932 & 3.03 & 0.003 \\
\cline { 2 - 5 } & Inguinal & 40 & 1.85 & 0.834 & & \\
\hline
\end{tabular}

When the mean number of puncture attempts in both groups were analysed, inguinal group had a less mean value $(1.85 \pm 0.834)$ ) compared to classic group (2.45 \pm 0.932$)$ which was statistically significant. ( $\mathrm{t}$ value $-3.03 ; \mathrm{p}$ value - 0.003 )

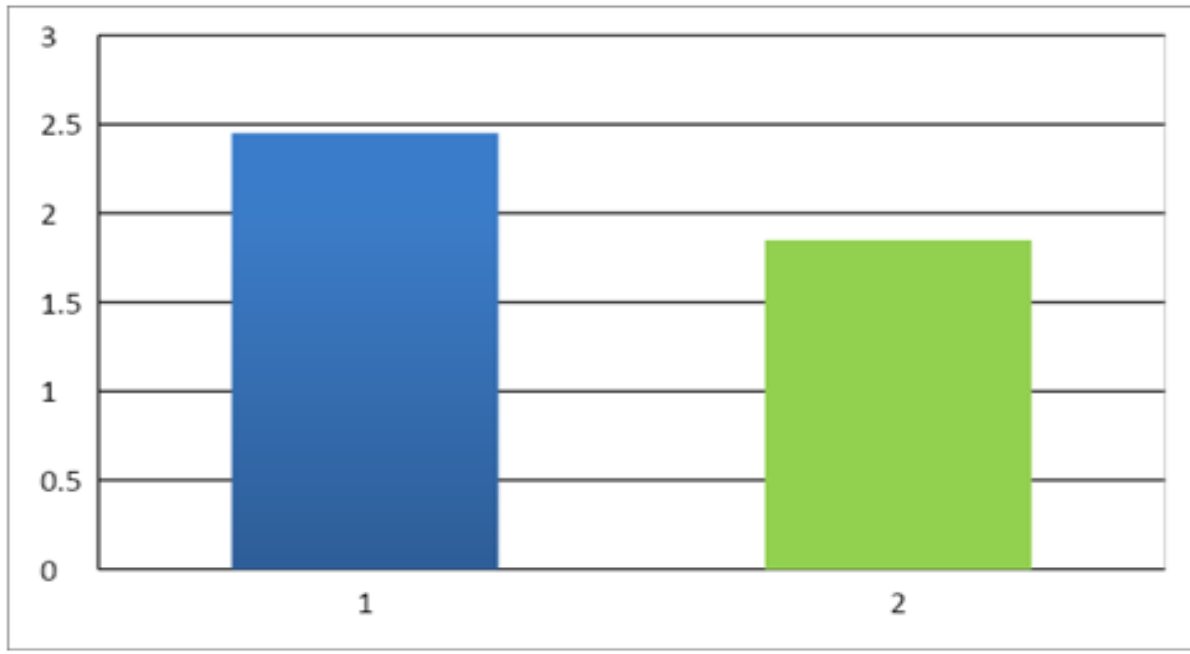

Graph 4: Mean number of puncture attempts to locate obturator nerve in both groups

Table 5: Incidence of accidental arterial puncture in both groups

\begin{tabular}{|l|c|c|c|c|}
\hline \multirow{2}{*}{ Group } & & \multicolumn{2}{|c|}{ Arterial Puncture } & \multirow{2}{*}{ Total } \\
\cline { 3 - 4 } Classic & Count & 38 & Yes & \\
\cline { 2 - 5 } & $\%$ & $95.0 \%$ & 2 & 40 \\
\hline \multirow{2}{*}{ Inguinal } & Count & 40 & 0 & $100.0 \%$ \\
\cline { 2 - 5 } & $\%$ & $100.0 \%$ & $0.0 \%$ & 40 \\
\hline \multirow{2}{*}{ Total } & Count & 78 & 78 & 2 \\
\cline { 2 - 5 } & $\%$ & $97.5 \%$ & $97.5 \%$ & $2.5 \%$ \\
\hline
\end{tabular}

Accidental arterial puncture occurred in two cases, both were in the classic group, but was not statistically significant. $\left(x^{2}=2.05 ; \mathrm{p}>0.05\right)$

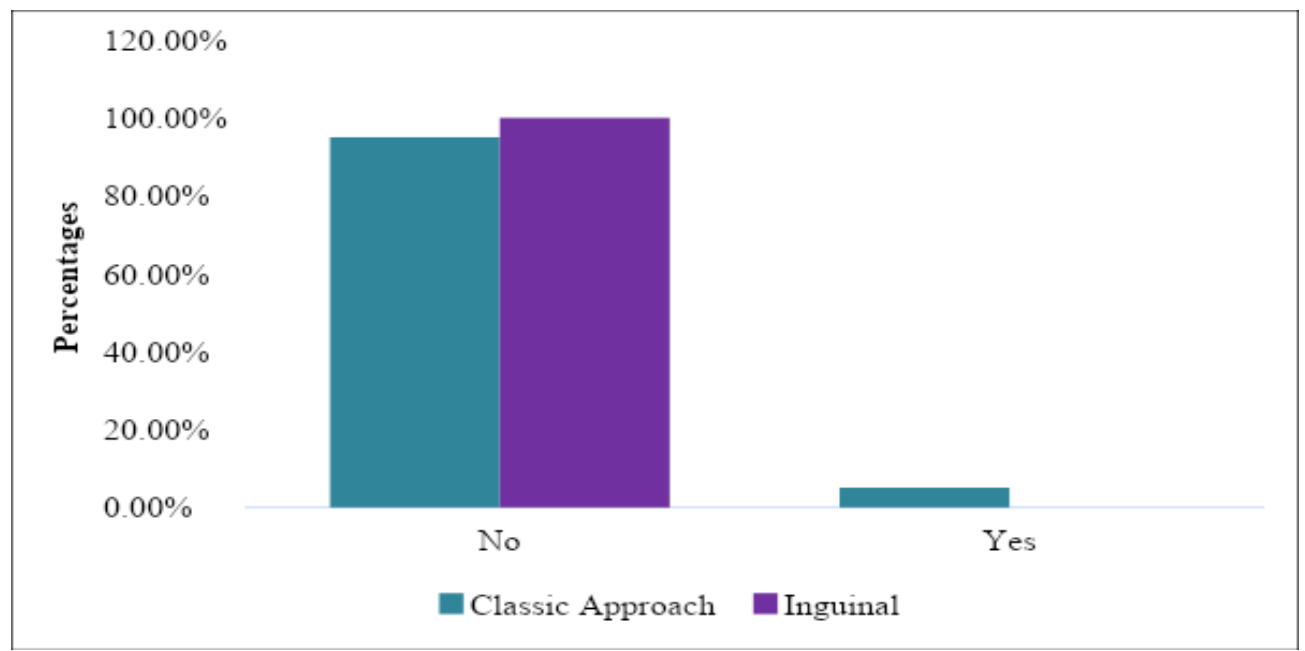

Graph 5: Incidence of accidental arterial puncture in both groups 
Table 6: Relationship between BMI and adductor jerk/obturator reflex

\begin{tabular}{|l|c|c|c|c|c|c|}
\hline \multirow{2}{*}{ Adductor jerk } & & \multicolumn{4}{|c|}{ BMI } & \multirow{2}{*}{ Total } \\
\cline { 3 - 7 } & & Underweight & Normal & Pre Obese & Obese class I & \\
\cline { 2 - 7 } & Count & 6 & 52 & 8 & 1 & 67 \\
\hline \multirow{2}{*}{ Yes } & $\%$ & $9.0 \%$ & $77.6 \%$ & $11.9 \%$ & $1.5 \%$ & $100.0 \%$ \\
\cline { 2 - 7 } & Count & 1 & 5 & 5 & 2 & 13 \\
\hline \multirow{2}{*}{ Total } & $\%$ & $7.7 \%$ & $38.5 \%$ & $38.5 \%$ & $15.4 \%$ & $100.0 \%$ \\
\cline { 2 - 7 } & Count & 7 & 57 & 13 & 3 & 80 \\
\cline { 2 - 7 } & $\%$ & $8.8 \%$ & $71.3 \%$ & $16.3 \%$ & $3.8 \%$ & $100.0 \%$ \\
\hline
\end{tabular}

There was a positive correlation between BMI and incidence of adductor jerk .Out of the total 13 cases where adductor jerk occurred, only $7.7 \%$ occurred in the underweight group, while its incidence was $38.5 \%$ in both the normal and pre obese subgroups. $\left.{ }^{x^{2}}=10.23 ; \mathrm{p}<0.05\right)$

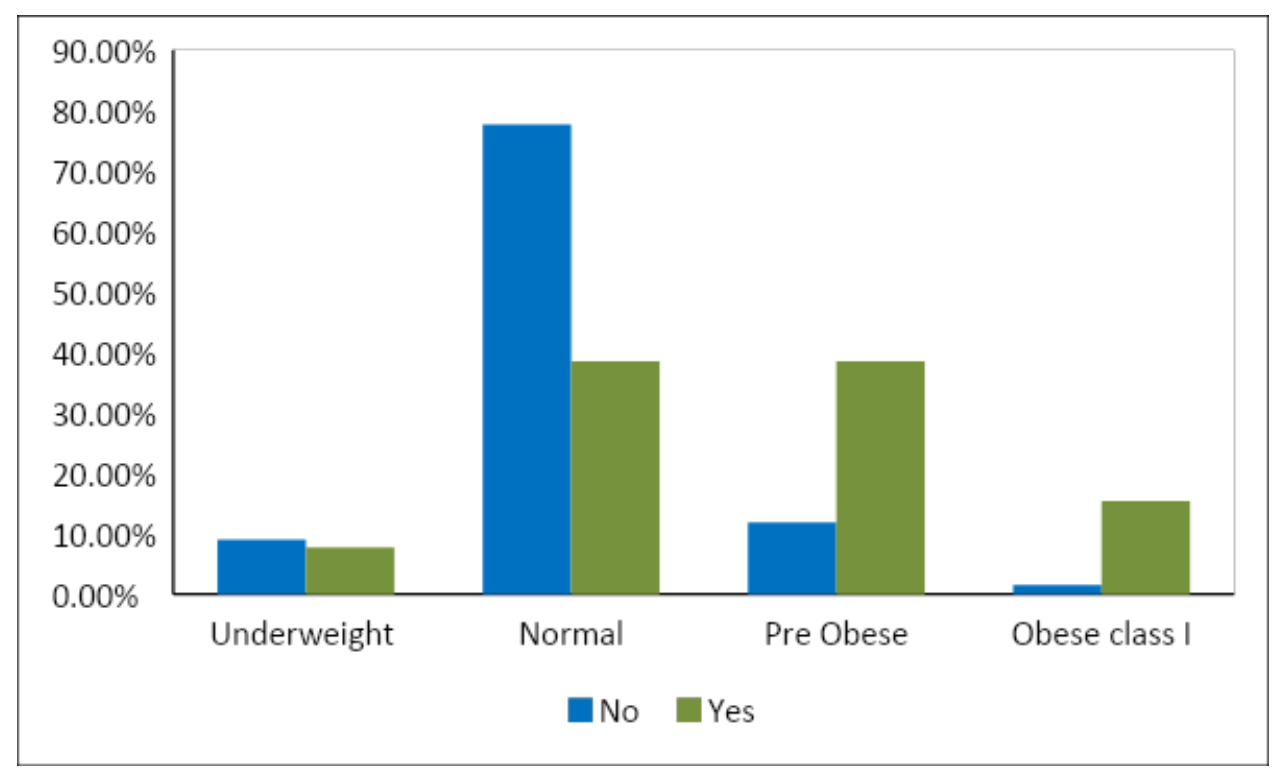

Graph 6: Relationship between BMI and adductor jerk/obturator reflex

\section{BMI and Number of Attempts}

Table 7: Relationship between BMI and number of puncture attempts

\begin{tabular}{|l|c|c|c|c|c|c|}
\hline & $\begin{array}{c}\text { Number of } \\
\text { attempts }\end{array}$ & Mean & Std. Deviation & Std. Error & $\mathrm{F}$ & $\mathrm{p}$ \\
\hline Underweight & 7 & 2.14 & 1.069 & .404 & \multirow{2}{*}{4.07} & \multirow{2}{*}{0.010} \\
\hline Normal & 57 & 2.00 & .824 & .109 & & \\
\hline Pre Obese & 13 & 2.46 & 1.050 & .291 & & \\
\hline Obese class I & 3 & 3.67 & .577 & .333 & & \\
\hline Total & 80 & 2.15 & .929 & .104 & & \\
\hline
\end{tabular}

The number of puncture attempts required to successfully locate the nerve had a positive correlation with BMI which showed an increasing trend along with BMI (Fig. 20) that was statistically significant ( $\mathrm{F}$ test value $4.07 ; \mathrm{p}-$ $0.010)$. The mean number of attempts was $(2.14 \pm$ 1.069) in the underweight group compared to $(3.67 \pm 0.577)$ in the Obese class 1 group. 


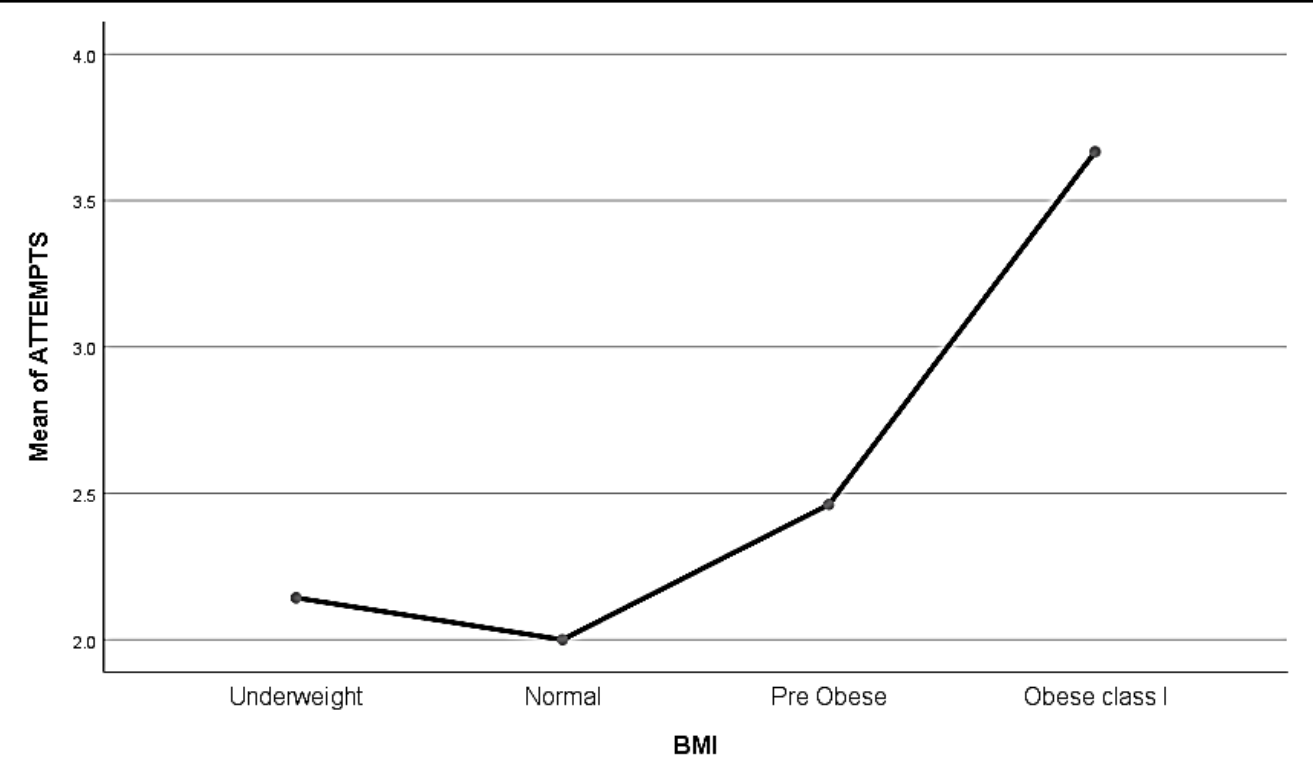

\section{Results}

The success rate of the block was defined by the number of cases in which obturator reflex/adductor jerk is prevented after administration of block.

Out of the 80 patients, 13 patients developed adductor jerk during surgery after administration of ONB. There was a statistically significant difference in the incidence of adductor jerk ( $p$ value <0.05) between the two groups with inguinal group having less incidence of the same (7.5\%) compared to the classic group (25\%).

The ease of block was defined by the number of attempts required to elicit adductor muscle contraction using peripheral nerve stimulator in order to locate the nerve and to administer local anaesthetic.

The mean number of puncture attempts in the inguinal group was less $(1.85 \pm 0.834)$ compared to classic group $(2.45 \pm 0.932)$ which was statistically significant. ( $\mathrm{p}$ value -0.003 )

Accidental arterial puncture occurred in two cases, both were in the classic group, but was not statistically significant. ( $\mathrm{p}$ value $>0.05$ )

The number of puncture attempts required to successfully locate the nerve had a positive correlation with BMI which showed an increasing trend along with BMI that was statistically significant ( $p$ value 0.010 ) indicating the decreased ease of block with increasing BMI.
There was a positive correlation between BMI and incidence of adductor jerk. Out of the total 13 cases where adductor jerk occurred, only $7.7 \%$ occurred in the underweight group, while its incidence was $38.5 \%$ in both the normal and pre obese subgroups ( $p$ value $<0.05$ )

\section{Discussion}

Selective blockade of the obturator nerve following spinal anesthesia would be mandatory as the complications associated with the adductor jerk/obturator reflex are relatively high. Approaches with varying levels of difficulty in achieving a successful block are still in place but the classic approach is commonly performed. The results of our study show that the inguinal approach would be an effective and safe alternative to the classic approach.

A total of 80 patients were enrolled in our study. They were divided into two groups of 40 each and both groups were comparable with respect to age, sex, ASA status. We compared the ease of block and success rate of the classic pubic approach and superficial inguinal approach for obturator block in patients undergoing TURBT under spinal anesthesia.

In our study, the success rate was defined as the absence of any post-block contraction of the adductor longus muscle during surgery and the ease of block was defined by the number of 
attempts required to elicit adductor muscle contraction using peripheral nerve stimulator in order to locate the nerve and to administer local anaesthetic.

The success rate was significantly higher in the inguinal approach with a lower number of puncture attempts than in the classic approach.

The incidence of adductor jerk in the inguinal was less $(7.5 \%)$ compared to the classic group (25\%).

These findings on the success rate and ease of block are similar to those in a study by Aghamohammadi et $\mathrm{al}^{12}$, where the success rate of ONB was significantly higher in the inguinal group $(97.1 \%$ vs. $71.4 \% ; p=0.003)$. The number of puncture attempts in the classic group was more than that in the inguinal group $(3.71 \pm 1.10$ vs. 1.66 \pm 0.68 , respectively; $\mathrm{P}<0.001$ ).

The findings on ease of block was similar to the study conducted by Jo et al who reported a lower number of puncture attempts (ease of block) in the inguinal ONB than in the classic ONB.

In contrast, Moningi et $\mathrm{al}^{7}$ reported that the number of puncture attempts showed no significant difference between inguinal and classic ONB procedures. The ease of the block was comparable with both the approaches $(p=0.09)$. Overall, the median number of attempts to accomplish the block was same in both groups $(p=0.45)$. There were no complications associated with inguinal approach, whereas there were four instances of vascular puncture $(p=$ 0.056) with the classic approach.

The relationship between BMI and the number of attempts were comparable with the results in the study by Aghamohammadi et $\mathrm{al}^{9}$ where the number of puncture attempts in the obese patients was clinically higher than that in the normal BMI patients $(2.5 \pm 1.24$ vs $1.8 \pm 0.75)$

Prentiss et $\mathrm{al}^{11}$ reported a $20 \%$ incidence of adductor jerk in patients who underwent transurethral resection for laterally located bladder cancers. In the current study, 25\% (10 out of 40) of patients in the classic group had adductor jerk/obturator reflex. This higher incidence of adductor jerk/obturator reflex in the classic approach is in contrast with study especially that by Moningi et $\mathrm{al}^{7}$ and Aghamohammadi et $\mathrm{al}^{9}$, who found just 1 case of adductor jerk with classic ONB.

\section{Limitations of the Study}

1. Peripheral nerve stimulator was used for performing the block. Ultrasound guidance could improve the safety and certainty of the block by confirming the position of the needle.

2. The precise anatomical localisation of the tumour in the bladder wall was not possible and may have influenced the results.

\section{Conclusion}

This study was done to compare the success rate and ease of block of inguinal and classic approach for obturator nerve block in patients undergoing transurethral resection of bladder tumour under spinal anesthesia. We conclude that compared to the classic approach, the inguinal approach for obturator nerve block during TURBT appeared to be an easily performable, effective block with a high success rate.

\section{References}

1. Burger, M., Catto, J.W., Dalbagni, G. et al. Epidemiology and risk factors of urothelial bladder cancer.Eur Urol. 2013; 63: 234-241

2. Beer E. Removal of neoplasms of the urinary bladder; a new method, employing high frequency (oudin) currents through a catheterizing cystoscope. JAMA 1910; 54: 1768-9.

3. Ukai R, Kawashita E, Ikeda H. A new technique for transurethral resection of superficial bladder tumor in 1 piece. $J$ Urol2000; 163: 878-9

4. G. Labat, Regional Anesthesia, Its Technic and Clinical Application, WB Saunders, Philadelphia, Pa, USA, 1st edition, 1922.

5. M. R. Wassef, "Interadductor approach to obturator nerve blockade for spastic conditions of adductor thigh 
muscles," Regional Anesthesia, vol. 18, no. 1, pp. 13-17, 1993.

6. O. Choquet, X. Capdevila, K. Bennourine, J.-L. Feugeas, S. Bringuier-Branchereau, and J.-C. Manelli, "A new inguinal approach for the obturator nerve block: anatomical and randomized clinical studies," Anesthesiology, vol. 103, no. 6, pp. 1238-1245, 2005.

7. Moningi S, Durga P, Ramachandran G, Murthy PV, Chilumala RR. Comparison of inguinal versus classic approach for obturator nerve block in patients undergoing transurethral resection of bladder tumors under spinal anesthesia. J Anaesthesiol Clin Pharmacol. 2014;30:415. doi: 10.4103/0970-9185.125702.

8. Jo YY, Choi E, Kil HK. Comparison of the success rate of inguinal approach with classical pubic approach for obturator nerve block in patients undergoing TURB. Korean J Anesthesiol. 2011;61:143-7. doi: 10.4097/kjae. 2011. 61.2.143.

9. Aghamohammadi D, Gargari RM, Fakhari S, Bilehjani E, Poorsadegh S. Classic versus Inguinal Approach for Obturator Nerve Block in Transurethral Resection of Bladder Cancer under Spinal Anesthesia: A Randomized Controlled Trial. Iran J Med Sci. 2018 Jan;43(1):75-80.

10. Miller R D. Miller's Anaesthesia. $8^{\text {th }}$ ed. Philadelphia: Elsevier Inc.;1939

11. Prentiss RJ, Harvey GW, Bethard WF, Boatwright DE, Pennington RD. Massive adductor muscle contraction in transurethral surgery: Cause and prevention; development of electrical circuitry. J Urol. 1965; 93:263-71. 